$1800^{\circ} \mathrm{C}$ 时出现双峰. Woodriff 等报道了氯化物基 体影响 $\mathrm{Pb}$ 的吸收峰变宽, $\mathrm{CuCl}_{2}$ 和 $\mathrm{CaCl}_{2}$ 存在, $\mathrm{Pb}$ 出现双峰. 但是, 加热较长端的石墨管, $\mathrm{CaCl}_{2}$ 存在 也只出现单峰. 我们的实验表明, 纯 $\mathrm{Pb}\left(\mathrm{NO}_{3}\right)_{2}$ 溶 液不出现双峰. 试验了五种氯化物基体使铅原子的 消失有不同程度的降低, 增长了停留时间和减少原 子化时间, 并使 $\mathrm{Pb}$ 的吸收峰变宽和吸收信号曲线的 衰减部分延长. 而 $\mathrm{CuCl}_{2}$ 和 $\mathrm{FeCl}_{3}$ 存在导致 $\mathrm{Pb}$ 的 不对称的吸收峰, 呈现双峰.

原子化时间是与原子化器表面性质, 加热速度 和试样组成有关, 而与原子化的试样量无关. 原子 化时间的改变, 反映了原子化过程的变化. 氯化物 基体引起铅的原子化时间缩短, 表明在原子化之前 可能形成易挥发的氯化物. $\mathrm{CuCl}_{2}$ 和 $\mathrm{FeCl}_{3}$ 是不稳 定的过渡元素氯化物, 低温热分解 $\mathrm{FeCl}_{3} \longrightarrow \mathrm{FeCl}_{2}$ $\left(315^{\circ} \mathrm{C}\right), \mathrm{CuCl}_{2} \longrightarrow \mathrm{CuCl}\left(993^{\circ} \mathrm{C}\right)$, 析出的氯使石墨 管表面有更多的 $\mathrm{PbO}$ 或 $\mathrm{Pb}$ 转变成 $\mathrm{PbCl}_{2}, \mathrm{PbCl}_{2}$ ( $\mathrm{B}$. $\left.\mathrm{P}=950^{\circ} \mathrm{C}\right)$ 的挥发性大于 $\mathrm{PbO}\left(\mathrm{M} . \mathrm{P}=886^{\circ} \mathrm{C}\right)$ 和 $\mathrm{Pb}\left(\mathrm{B} . \mathrm{P}=1740^{\circ} \mathrm{C}\right)$, 使之更易蒸发. 其次, 石墨管 表面 $\mathrm{PbO}$ 的热分解和还原反应亦形成 $\mathrm{Pb}$. 从铅的 原子消失速度常数和停留时间的计算值的比较表 明, 受吸收峰之后相继原子化产生的自由原子铅对 停留时间的影响, 纯 $\mathrm{Pb}\left(\mathrm{NO}_{3}\right)_{2}$ 要比有 $\mathrm{CuCl}_{2}$ 和 $\mathrm{FeCl}_{3}$ 存在时少得多. 所以,石墨炉中原子的形成速 度支配着吸收信号曲线的形状. $\mathrm{CuCl}_{2}$ 和 $\mathrm{FeCl}_{3}$ 对 铅的吸收信号的影响，可能是通过在石墨管表面的 化学反应改变了铅的原子化过程. 其影响的机理正 在进一步研究. 详细的结果将另文发表.

郑衍生 刘烟生 (吉林大学化学系,长春)

\title{
山西太原组海相石灰岩层及煤层之对比
}

太原组是山西晚古生代主要含煤岩系之一。太 原组为海陆交替相沉积, 山西各地太原组中含丰富 海相动物化石的石灰岩层之间的正确对比，成为上 述地区太原组煤层之间正确对比的关键.

在太原西山玉门沟, 太原组层型剖面的石灰岩 层及主要煤层的层序自下而上为: 吴家峪灰岩、八 尺煤、丈五煤、庙沟灰岩、毛沟灰岩、下三尺煤、斜道 灰岩、七尺煤、东大窑灰岩及新七尺煤.

根据野外调查和笯类等海相动物群对比的资 料，山西石炭系各主要分布区内太原组海相灰岩层 的对比关系如下：保德地区的扒楼沟灰岩、陵川地 区的后寺灰岩 $\left(\mathrm{L}_{0}\right)$ 应与太原西山吴家峪灰岩相当.

阳泉地区的四节灰岩、陵川地区的松窑沟灰岩 $\left(L_{1}\right)$ 、霍县地区的 $K_{2}$ 灰岩应与太原西山庙沟和毛 沟灰岩相当; 朔县地区的芦家窑灰岩、保德地区的保 德灰岩应与太原西山毛沟灰岩相当.

阳泉地区的钱石灰岩、陵川地区的老金沟灰岩 $\left(L_{2}\right) 、$ 霍县地区的 $K_{3}$ 灰岩、保德地区的土门页岩应 与太原西山斜道灰岩相当。
阳宗地区的猴石灰岩、陵川地区的红矾沟灰岩 $\left(L_{3}\right)$ 、霍县地区的 $K_{4}$ 灰岩应与太原西山东大窑灰 岩相当.

根据海相灰岩层的上述对比，山西石炭系各主 要分布区内太原组的煤层对比关系如下：阳泉地区 的丈八煤、陵川地区的臭煤、霍县地区的丈八煤和毛 四尺煤、宁武地区的上冒丈煤、保德地区的 $\mathrm{E}$ 煤组、 朔县地区的五米煤应与太原西山八尺煤和丈五煤相 当.

阳泉地区的钱石下煤、霍县地区的铜二尺煤、宁 武地区的拉它煤、保德地区的 $D$ 煤组中下部应与太 原西山下三尺煤相当.

阳泉地区的四尺煤、霍县地区的铜三尺煤、宁武 地区的腰渣煤、朔县地区的下二十米煤、保德地区 D 煤组上部应与太原西山七尺煤相当.

陵川地区的半香煤(黄煤)应与太原西山新七尺 煤相当.

$$
\text { 张志存 }
$$

(山西省区域地质调查队,榆次)

\section{YAG 激光对口腔癌、食道癌组织选择性作用的研究}

实验表明,在特定情况下, YAG 激光对口腔癌、 食道癌有选择性作用.

实验 1 用 YAG 激光,以特定的方式，同时
照射人口腔癌及近旁正常组织. 通过观察和病理切 片分析，可以明显地看到选择性作用. 在激光照射 下, 癌组织颜色变深; 2 天后脱落. 正常组织无明显 
损份. 共观察患者 19 例, 其中 10 例瘤体完全脱落, 8 例癌病灶大大缩小，仅 1 例由于中途停止治疗而 无效。实验已进行 1 年多，尚末见复发现象。远期 伃效待继续观察. 该方法的优点是有选择性作用, 简单易行,无副作用,患者不用避光.

实验 21982 年 6 月, 我们用 $\mathrm{YAG}$ 激光照 射晚期食道癌患者 16 例。照射方法同上. 照射是 通过内窥镜进行的. 通过内窥镜可以观察到食道癌 的变化过程与口腔癌相似. 照射后 2 天进行胸部 $x$ 光透视. 其中髓质型和菌伞型癌共 6 例, 全部有效, 痱块脱落, 正常组织看不出损伤, 可以看出选择性作 月. 其余 10 例系缩窄型㾔, 治疗效果不明显.

形成选择性作用的原因分析如下:

（1）吸收光谱的差异造成的选择性作用：论据 如下: 实验 1 , 将人口腔㿋、食道癌及正常粘膜均做 成生物切片, 不染色. 用分光光度计测星, 在波长 1.06 微米, 癖的消光系数明显的莶于正党粘膜. 实 验 2 , 将人口腔癌、食道瘁和正常粘膜的鲜样品均做 成相间尺寸的方块. 用 YAG 激光照射, 以半导休 濯度计测䥣. 可以看到, 癌组织温度高于正常粘膜. 实验 3 , 用 YAG 激光以相同的条件照射人口腔癌及 癌旁正: 常组织. 以半导体温度计测量, 结果表明癌 组织温度高于正常组织. 实验 1,2 之间的差异在于
水;实验 2、3 之间的差异在于血.

（2）表面渗血造成的选择性作用：在临床实验 中可以看到这样的现象, 如照射方法合适,能使癌表 面渗血, 颜色变深, 吸收激光能力增强, 引起颜色进 一步变深, ……如此循环下去, 直至癌组织被破坏; 正常组织无此现象, 不受损伤. 形成选择性作用.

（3）癌细胞热敏感现象造成的选择性作用: 癌 细胞对热敏感，则形成选择性作用. 这一现象是人 们已知的.

此外, 对痛组织及正常粘膜吸收光谱进行测量、 分析,实验指出了采用 YAG 激光治癌的合理性。

\section{徐业林 陶保平苏万芳 \\ 江 玲 甘大清}

(中国科学院生物物理研究所, 北京) 朱宣智徐 明 隋良朋 王勉镜 李锡瑾 娄铁尘 （北京口腔医院）

郭少陵

(北京光电技术研究所)

李章才 秦国祥

（河南省林县人民医院） 